\title{
Article \\ Effect of Subclinical Hypothyroidism on the Association between Hemoglobin A1c and Reduced Renal Function: A Prospective Study
}

\author{
Yuji Shimizu ${ }^{1,2, *}$, Shin-Ya Kawashiri ${ }^{3,4}$, Yuko Noguchi ${ }^{3}$, Seiko Nakamichi ${ }^{1,5}$, Yasuhiro Nagata ${ }^{3,4}$, \\ Takahiro Maeda ${ }^{1,4}$ and Naomi Hayashida ${ }^{4,6}$
}

check for

updates

Citation: Shimizu, Y.; Kawashiri,

S.-Y.; Noguchi, Y.; Nakamichi, S.;

Nagata, Y.; Maeda, T.; Hayashida, N. Effect of Subclinical Hypothyroidism on the Association between

Hemoglobin A1c and Reduced Renal Function: A Prospective Study.

Diagnostics 2022, 12, 462. https:// doi.org/10.3390/diagnostics12020462

Academic Editor: Akito Maeshima

Received: 13 January 2022

Accepted: 8 February 2022

Published: 11 February 2022

Publisher's Note: MDPI stays neutral with regard to jurisdictional claims in published maps and institutional affiliations.

Copyright: (c) 2022 by the authors. Licensee MDPI, Basel, Switzerland. This article is an open access article distributed under the terms and conditions of the Creative Commons Attribution (CC BY) license (https:// creativecommons.org/licenses/by/ $4.0 /)$.
1 Department of General Medicine, Nagasaki University Graduate School of Biomedical Sciences, Nagasaki 852-8501, Japan; seiko-n@nagasaki-u.ac.jp (S.N.); tmaeda@nagasaki-u.ac.jp (T.M.)

2 Department of Cardiovascular Disease Prevention, Osaka Center for Cancer and Cardiovascular Diseases Prevention, Osaka 537-8511, Japan

3 Department of Community Medicine, Nagasaki University Graduate School of Biomedical Sciences, Nagasaki 852-8523, Japan; shin-ya@nagasaki-u.ac.jp (S.-Y.K.); y-noguti@nagasaki-u.ac.jp (Y.N.); ynagata1961@nagasaki-u.ac.jp (Y.N.)

4 Leading Medical Research Core Unit, Nagasaki University Graduate School of Biomedical Sciences, Nagasaki 852-8523, Japan; naomin@nagasaki-u.ac.jp

5 Nagasaki University Health Center, Nagasaki 852-8521, Japan

6 Division of Promotion of Collaborative Research on Radiation and Environmental Health Effects, Atomic Bomb Disease Institute, Nagasaki University, Nagasaki 852-8523, Japan

* Correspondence: shimizul@osaka-ganjun.jp; Tel.: +81-95-819-7578

\begin{abstract}
Subclinical hypothyroidism (SCH) was reported to be associated with accelerating endothelial dysfunction, which is recognized as one of the upstream mechanisms that leads to glomerular injury (lower glomerular filtration rate (GFR)). SCH was also reported to be associated with hyperglycemia, which is associated with higher hemoglobin A1c (HbA1c) levels and induces endothelial dysfunction. Therefore, $\mathrm{SCH}$ status could influence the association between $\mathrm{HbA} 1 \mathrm{c}$ and reduced eGFR. To clarify those associations, we conducted a prospective study of 1580 Japanese individuals who participated in an annual health check-up in 2014 with 2.8 years of follow-up. All participants had free triiodothyronine (T3) and free thyroxine (T4) levels in the normal range. Among study participants, 88 were diagnosed as having $\mathrm{SCH}$. Even though no significant correlation was observed between $\mathrm{HbA} 1 \mathrm{c}$ and annual change in estimated GFR among participants without SCH (multiadjusted standardized parameter estimate $(\beta)=0.03, p=0.250)$, a significant inverse association was observed among participants with $\mathrm{SCH}(\beta=-0.26, p=0.014)$. When those analyses were performed among participants who were not taking glucose lowering medication, the observed associations were essentially the same: $\beta=0.03, p=0.266$ for participants without $\mathrm{SCH}$ and $\beta=-0.32, p=0.006$ for participants with $\mathrm{SCH}$, respectively. Therefore, $\mathrm{SCH}$ status could influence the association between $\mathrm{HbA} 1 \mathrm{c}$ and renal function.
\end{abstract}

Keywords: subclinical hypothyroidism; thyroid stimulating hormone; triiodothyronine; HbA1c; renal function; GFR

\section{Introduction}

Subclinical hypothyroidism (SCH), which is defined as elevated levels of thyroidstimulating hormone (TSH) with free triiodothyronine (T3) and thyroxine (T4) levels in the normal range, was reported to be associated with accelerating endothelial dysfunction [1] Recent studies have reported a close connection between thyroid hormones and endothelial maintenance. Thyroid hormones directly stimulate hematopoietic stem cells [2], which can differentiate into endothelial progenitor cells $[3,4]$ that can promote thyroid follicle formation $[5,6]$. Since endothelial progenitor cells play an important role in endothelial 
repair $[3,4,7]$ and thyroid follicle cells produce thyroid hormones, the production of thyroid hormones might be associated with endothelial repair capacity. SCH could be associated with accelerating endothelial dysfunction [1].

On the other hand, hyperglycemia, which is associated with higher hemoglobin A1c (HbA1c) levels, is known to induce endothelial dysfunction [8]. Endothelial dysfunction is recognized as one of the upstream mechanisms that leads to glomerular injury, which is associated with reducing the glomerular filtration rate (GFR) [9]. Therefore, higher HbA1c levels could be associated with reduced renal function [10]. Appropriate endothelial repair might mask this association between $\mathrm{HbA} 1 \mathrm{c}$ levels and reduced renal function while the presence of SCH might indicate inappropriate endothelial repair.

Therefore, we hypothesized that higher $\mathrm{HbA1c}$ levels are significantly associated with reduced renal function as evaluated by annual changes in estimated GFR (eGFR) in individuals with SCH but not in individuals without SCH. To clarify these associations, we conducted a prospective study with a mean follow-up of 2.8 years (standard deviation (SD), 0.5; range 0.8-3.2) of 1580 Japanese individuals with in normal thyroid hormone (i.e., free T3 and free T4 levels in the normal range) aged 40-74 years who participated in an annual health check-up in 2014.

\section{Materials and Methods}

\subsection{Study Population}

Methods related to the present risk survey, including evaluation of thyroid function, have been described elsewhere [11]. We ensured that participants understood the study's objectives and provided informed consent. This study was approved by the ethics committee of the Nagasaki University Graduate School of Biomedical Sciences (project registration number: 14051404).

The study population comprised 1883 Japanese individuals between the ages of 40 and 74 years from Saza town in western Japan who underwent an annual medical check-up in 2014, as recommended by the Japanese government.

To avoid the influence of thyroid disease, we excluded all participants with a history of thyroid disease $(n=60)$. We also excluded participants with missing data on thyroid function, such as TSH, free T3, and free T4 $(n=17)$, and participants with abnormal free T3 and free T4 levels $(n=77)$. In addition, participants without baseline HbA1c or eGFR data $(n=2)$ and participants without eGFR data in 2015-2017 were also excluded $(n=147)$. The remaining 1580 participants, with a mean age of 60.9 years (SD, 8.9; range $40-74)$, were included in the study.

\subsection{Data Collection and Laboratory Measurments}

Trained interviewers obtained information on the use of glucose-lowering medication. A fasting blood sample was collected. TSH, free T3, and free T4 levels were measured using a chemiluminescent immunoassay at the LSI Medience Corporation (Tokyo, Japan). The normal range for free T3 (2.1-4.1 pg/mL), free T4 (1.0-1.7 ng/dL), and TSH (0.39-4.01 $\mu \mathrm{IU} / \mathrm{mL})$ using this method was demonstrated elsewhere [12]. SCH was defined as TSH $>4.01 \mu \mathrm{IU} / \mathrm{mL}$ and normal free T3 and free T4 levels. By following the report from the committee of the Japan Diabetes Society, we also defined diabetes as HbA1c $\geq 6.5 \%$ and/or taking glucose lowering medication [13].

Serum creatinine concentrations were measured using a standard laboratory procedure at SRL, Inc. (Tokyo, Japan). eGFR was calculated with an established method recently adapted by a working group of the Japanese Chronic Kidney Disease Initiative [14]: eGFR $\left(\mathrm{mL} / \mathrm{min} / 1.73 \mathrm{~m}^{2}\right)=194 \times(\text { serum creatinine }(\text { enzyme method }))^{-1.094} \times(\text { age })^{-0.287} \times$ (0.739 for women). Annual change in eGFR (annual $\triangle \mathrm{eGFR}$ ) was calculated as annual $\triangle \mathrm{eGFR}\left(\left[\mathrm{mL} / \mathrm{min} / 1.73 \mathrm{~m}^{2}\right] /\right.$ year $)=$ [endpoint eGFR $\left(\mathrm{mL} / \mathrm{min} / 1.73 \mathrm{~m}^{2}\right)$-baseline eGFR $\left(\mathrm{mL} / \mathrm{min} / 1.73 \mathrm{~m}^{2}\right)$ ]/[endpoint date-baseline date]. 


\subsection{Statistical Analysis}

Characteristics of the study participants by SCH status were expressed as means $\pm \mathrm{SD}$, except for gender and glucose lowering medication use. Those variables were expressed as proportions.

Differences between mean values or proportions of characteristics were analyzed in relation to SCH status. Significant differences were evaluated using the $t$-test for continuous variables and the $\chi^{2}$ test for categorical variables.

Simple correlation analysis and multivariable linear regression analysis of annual decrease of eGFR based on diabetes status and SCH status adjusting for relevant confounding factors were performed. Renal function at baseline might influence annual $\Delta \mathrm{eGFR}$. Therefore, for the multivariable linear regression analysis, adjustments were made for sex, age, free $\mathrm{T}_{3}(\mathrm{pg} / \mathrm{mL})$, TSH $(\mu \mathrm{IU} / \mathrm{mL})$, and eGFR $\left(\mathrm{mL} / \mathrm{min} / 1.73 \mathrm{~m}^{2}\right)$.

Since diabetes could influence the main results, analysis limited to participants without diabetes was performed.

To avoid the influence of age on the present results, by using the age-matched sample, the association between $\mathrm{HbA} 1 \mathrm{c}$ and annual $\triangle \mathrm{eGFR}$ among participants without SCH was evaluated.

Glucose-lowering medication use could act as a strong confounder in the main analysis. As a sensitivity analysis, we also performed these analyses in a subset of participants who were not taking glucose-lowering medication.

All statistical analysis was performed with SAS for Windows, version 9.4 (SAS Inc., Cary, NC, USA). Values of $p<0.05$ were regarded as statistically significant.

\section{Results}

\subsection{Characteristics of Study Population by Subclinical Hypothyroidism (SCH) Status}

Among the study participants, 88 were diagnosed as having $\mathrm{SCH}$ and 140 were diagnosed as having diabetes. The characteristics of study participants by SCH status are shown in Table 1.

Table 1. Characteristics of study participants.

\begin{tabular}{cccc}
\hline & \multicolumn{2}{c}{ Subclinical Hypothyroidism } & \\
\cline { 2 - 3 } & $\mathbf{( - )}$ & $\mathbf{( + )}$ & \\
\hline No of participants & 1492 & 88 & \\
Men, \% & 36.7 & 39.8 & 0.566 \\
Age, year & $60.8 \pm 8.9$ & $62.6 \pm 8.9$ & 0.074 \\
free T3, (2.1-4.1) pg/mL & $3.2 \pm 0.3$ & $3.1 \pm 0.3$ & 0.084 \\
free T4, (1.0-1.7) ng/dL & $1.3 \pm 0.2$ & $1.2 \pm 0.2$ & $<0.001$ \\
TSH, (0.39-4.01) $\mu \mathrm{IU} / \mathrm{mL}$ & $1.7 \pm 0.8$ & $5.7 \pm 1.7$ & $<0.001$ \\
Diabetes, \% & 8.2 & 20.5 & $<0.001$ \\
Glucose lowering medication use, \% & 5.4 & 12.5 & $<0.001$ \\
HbA1c, \% & $5.6 \pm 0.6$ & $6.0 \pm 1.0$ & $<0.001$ \\
Serum creatinine, mg/dL & $0.75 \pm 0.33$ & $0.82 \pm 0.32$ & 0.069 \\
eGFR, mL/min/1.76m ${ }^{2}$ & $71.4 \pm 12.9$ & $67.0 \pm 15.0$ & 0.002
\end{tabular}

Values are means \pm SD. Normal ranges are given in parentheses. TSH, thyroid-stimulating hormone; T3, triiodothyronine; T4, thyroxine; HebA1, hemoglobin A1c; eGFR, estimated glomerular filtration rate.

Compared with participants without $\mathrm{SCH}$, participants with $\mathrm{SCH}$ had significantly higher values of TSH and HbA1C. Participants with SCH had a significantly higher prevalence of diabetes, glucose-lowering medication use and significantly lower values of free T4 and eGFR. Participants with SCH had lower free T3 values than participants without $\mathrm{SCH}$, but this difference was not statistically significant.

Figure 1 shows the distribution of annual $\triangle \mathrm{eGFR}$ by SCH status. Participants with and without SCH had essentially the same associations. 
a) Non-subclinical hypothyroidism

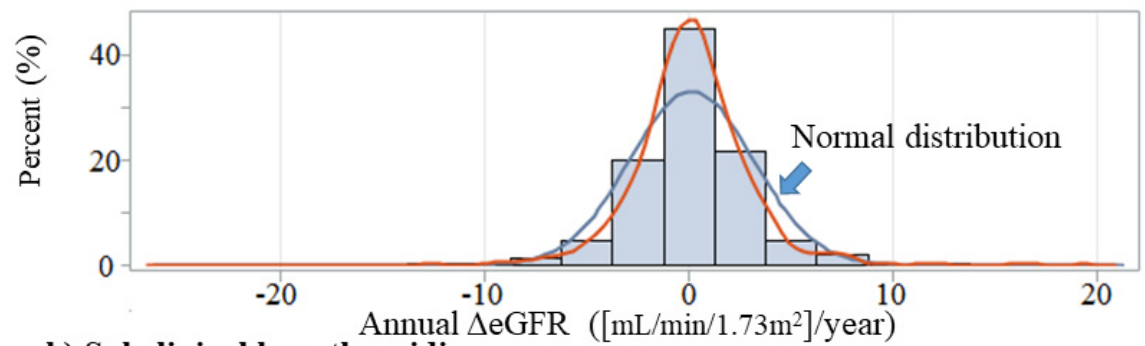

b) Subclinical hypothyroidism

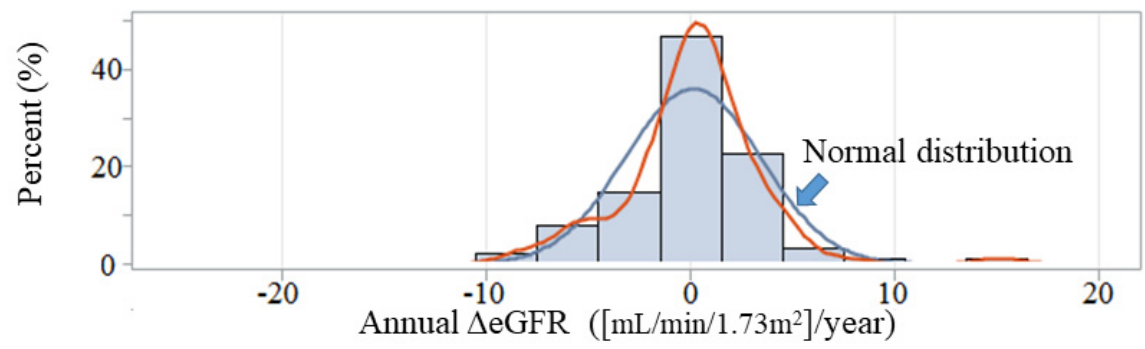

Figure 1. Annual change in eGFR by subclinical hypothyroidism status. Annual $\triangle \mathrm{eGFR}$ : annual change in estimated glomerular filtration rate $\left(\left[\mathrm{mL} / \mathrm{min} / 1.73 \mathrm{~m}^{2}\right] /\right.$ year$)$.

3.2. Correlations between Annual Change in Estimated Glomerular Filtration Rate ( $\triangle e G F R)$ and Hemoglobin A1c $(\mathrm{HbA1c})$ in Relation to Diabetes

Correlations between annual $\triangle \mathrm{eGFR}$ and $\mathrm{HbA} 1 \mathrm{c}$ for total participants and stratified by diabetes are shown in Table 2. Among total participants, both by simple correlation analysis and by multiple linear regression analysis, no significant associations between $\mathrm{HbA} 1 \mathrm{c}$ and annual $\triangle \mathrm{eGFR}$ were observed. These associations were also observed when the analyses were limited to participants with diabetes and limited to those without diabetes (Table 2).

Table 2. Simple correlation analysis and multivariable linear regression analysis of annual $\triangle \mathrm{eGFR}$ and relevant factors for total and by diabetes status.

\begin{tabular}{|c|c|c|c|c|}
\hline & \multirow{2}{*}{$\begin{array}{c}\text { Simple Correlation } \\
\text { Analysis } \\
\mathbf{r}(p)\end{array}$} & \multicolumn{3}{|c|}{ Multiple Linear Regression Analysis } \\
\hline & & B & $\beta$ & $p$ \\
\hline \multicolumn{5}{|c|}{ Total } \\
\hline No of participants & & 158 & & \\
\hline Sex (Men) & $-0.07(p=0.008)$ & -0.51 & -0.08 & 0.020 \\
\hline Age & $-0.03(p=0.320)$ & -0.02 & -0.06 & 0.028 \\
\hline free T3 & $-0.01(p=0.646)$ & 0.30 & 0.03 & 0.240 \\
\hline TSH & $-0.002(p=0.943)$ & -0.05 & -0.02 & 0.396 \\
\hline eGFR & $0.13(p<0.001)$ & -0.04 & -0.16 & $<0.001$ \\
\hline $\mathrm{HbA} 1 \mathrm{c}$ & $-0.02(p=0.417)$ & -0.01 & -0.002 & 0.938 \\
\hline \multicolumn{5}{|c|}{ Non-diabetes } \\
\hline No of participants & & 144 & & \\
\hline Sex (Men) & $-0.07(p=0.013)$ & -0.45 & -0.07 & 0.080 \\
\hline Age & $-0.03(p=0.196)$ & -0.02 & -0.07 & 0.012 \\
\hline free T3 & $-0.01(p=0.695)$ & 0.33 & 0.04 & 0.202 \\
\hline $\mathrm{TSH}$ & $0.02(p=0.528)$ & 0.002 & 0.001 & 0.979 \\
\hline eGFR & $-0.13(p<0.001)$ & -0.04 & -0.16 & $<0.001$ \\
\hline $\mathrm{HbA1c}$ & $0.001(p=0.970)$ & -0.01 & -0.001 & 0.982 \\
\hline
\end{tabular}


Table 2. Cont.

\begin{tabular}{|c|c|c|c|c|}
\hline & \multirow{2}{*}{$\begin{array}{c}\text { Simple Correlation } \\
\text { Analysis } \\
\mathrm{r}(p)\end{array}$} & \multicolumn{3}{|c|}{ Multiple Linear Regression Analysis } \\
\hline & & B & $\beta$ & $p$ \\
\hline \multicolumn{5}{|c|}{ Diabetes } \\
\hline No of participants & & 14 & & \\
\hline Sex (Men) & $-0.11(p=0.208)$ & -1.11 & -0.13 & 0.123 \\
\hline Age & $0.09(p=0.284)$ & 0.02 & 0.03 & 0.710 \\
\hline free T3 & $-0.03(p=0.721)$ & 0.18 & 0.01 & 0.870 \\
\hline TSH & $-0.08(p=0.358)$ & -0.33 & -0.14 & 0.113 \\
\hline eGFR & $-0.17(p=0.048)$ & -0.06 & -0.21 & 0.021 \\
\hline $\mathrm{HbA1c}$ & $0.01(p=0.884)$ & 0.26 & 0.06 & 0.530 \\
\hline
\end{tabular}

$\triangle \mathrm{GFR}$, change in estimated glomerular filtration rate; eGFR, estimated glomerular filtration rate; T3, triiodothyronine; TSH, thyroid-stimulating hormone; HebA1, hemoglobin A1c; r $(p)$, simple correlation coefficient ( $p$ value); B, parameter estimate; $\beta$, standardized parameter estimate.

\subsection{Correlations between Annual $\triangle e G F R$ and HbA1c by SCH Status among Participants without} Diabetes

Correlations between annual $\triangle \mathrm{eGFR}$ and $\mathrm{HbA} 1 \mathrm{c}$ by SCH status among participants without diabetes are shown in Table 2. In the simple correlation analysis, there was no significant correlation between $\mathrm{HbA1c}$ and annual $\triangle \mathrm{eGFR}$ in participants with and without $\mathrm{SCH}$. After adjusting for sex, age, free T3, TSH, and eGFR in a multivariable linear regression analysis, a significant inverse association between $\mathrm{HbA1c}$ and annual $\triangle \mathrm{eGFR}$ was observed in participants with SCH but not in participants without $\mathrm{SCH}$ (Table 3).

Table 3. Simple correlation analysis and multivariable linear regression analysis of annual $\triangle \mathrm{eGFR}$ and relevant factors by subclinical hypothyroidism among participants without diabetes.

\begin{tabular}{|c|c|c|c|c|}
\hline & \multirow{2}{*}{$\begin{array}{c}\begin{array}{c}\text { Simple Correlation } \\
\text { Analysis }\end{array} \\
\mathrm{r}(p)\end{array}$} & \multicolumn{3}{|c|}{ Multiple Linear Regression Analysis } \\
\hline & & B & $\beta$ & $p$ \\
\hline \multicolumn{5}{|c|}{ Non-Subclinical Hypothyroidism } \\
\hline No of participants & & 137 & & \\
\hline Sex (Men) & $-0.08(p=0.004)$ & -0.51 & -0.09 & 0.003 \\
\hline Age & $-0.05(p=0.094)$ & -0.03 & -0.09 & 0.003 \\
\hline free T3 & $-0.01(p=0.718)$ & 0.38 & 0.04 & 0.152 \\
\hline TSH & $0.02(p=0.574)$ & -0.02 & -0.01 & 0.857 \\
\hline eGFR & $-0.14(p<0.001)$ & -0.04 & -0.17 & $<0.001$ \\
\hline $\mathrm{HbA1c}$ & $0.01(p=0.759)$ & 0.08 & 0.01 & 0.736 \\
\hline \multicolumn{5}{|c|}{ Subclinical Hypothyroidism } \\
\hline No of participants & & 70 & & \\
\hline Sex (Men) & $0.13(p=0.266)$ & 1.72 & 0.26 & 0.055 \\
\hline Age & $0.14(p=0.239)$ & 0.10 & 0.27 & 0.038 \\
\hline free $\mathrm{T} 3$ & $0.001(p=0.996)$ & -1.24 & -0.11 & 0.386 \\
\hline $\mathrm{TSH}$ & $-0.12(p=0.338)$ & -0.29 & -0.14 & 0.248 \\
\hline eGFR & $0.07(p=0.557)$ & 0.03 & 0.11 & 0.416 \\
\hline $\mathrm{HbA1c}$ & $-0.17(p=0.167)$ & -2.58 & -0.25 & 0.049 \\
\hline
\end{tabular}

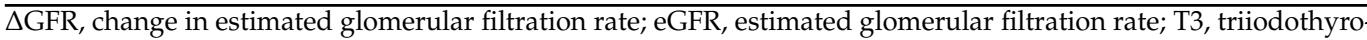
nine; TSH, thyroid-stimulating hormone; HebA1, hemoglobin A1c; $r(p)$, simple correlation coefficient ( $p$ value); $\mathrm{B}$, parameter estimate; $\beta$, standardized parameter estimate.

\subsection{Correlations between Annual $\triangle e G F R$ and HbA1c by SCH Status}

Correlations between annual $\triangle \mathrm{eGFR}$ and $\mathrm{HbA1}$ c by SCH status are shown in Table 2. In the simple correlation analysis, there was no significant correlation between $\mathrm{HbA} 1 \mathrm{c}$ and annual $\triangle \mathrm{eGFR}$ in participants without $\mathrm{SCH}$ and a significant inverse association in participants with $\mathrm{SCH}$. This inverse association shows linear association (Figure 2). After 
adjusting for sex, age, TSH, and free T3 in a multivariable linear regression analysis, the associations were essentially the same (Table 4).

a) Non-subclinical hypothyroidism

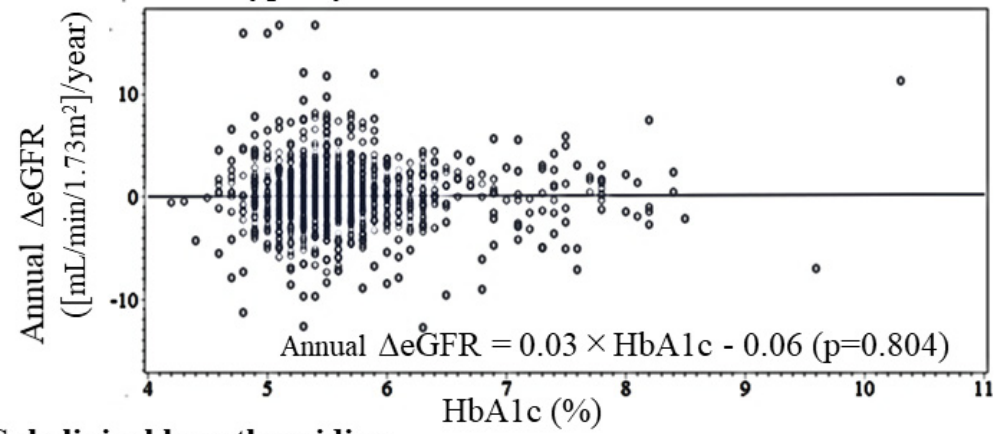

b) Subclinical hypothyroidism

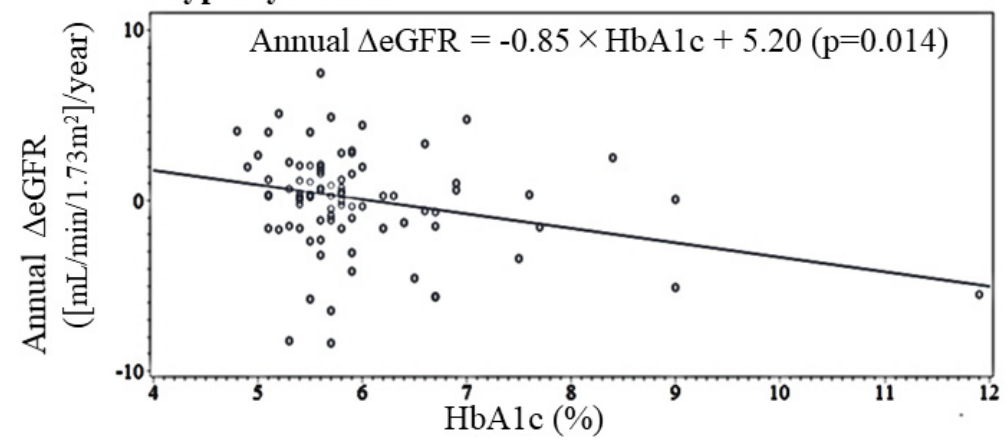

Figure 2. Simple linear regression analysis of $\mathrm{HbA1c}$ and annual change in eGFR by subclinical hypothyroidism status. Annual $\triangle \mathrm{eGFR}$ : annual change in estimated glomerular filtration rate $\left(\left[\mathrm{mL} / \mathrm{min} / 1.73 \mathrm{~m}^{2}\right] /\right.$ year$)$.

Table 4. Simple correlation analysis and multivariable linear regression analysis of annual $\Delta \mathrm{eGFR}$ and relevant factors by subclinical hypothyroidism status.

\begin{tabular}{|c|c|c|c|c|}
\hline & \multirow{2}{*}{$\begin{array}{c}\begin{array}{c}\text { Simple Correlation } \\
\text { Analysis }\end{array} \\
\text { r }(p)\end{array}$} & \multicolumn{3}{|c|}{ Multiple Linear Regression Analysis } \\
\hline & & B & $\beta$ & $p$ \\
\hline \multicolumn{5}{|c|}{ Non-Subclinical Hypothyroidism } \\
\hline No of participants & & 149 & & \\
\hline Sex (Men) & $-0.08(p=0.002)$ & -0.57 & -0.09 & $<0.001$ \\
\hline Age & $-0.04(p=0.161)$ & -0.03 & -0.08 & 0.003 \\
\hline free $\mathrm{T} 3$ & $-0.01(p=0.592)$ & 0.34 & 0.04 & 0.194 \\
\hline TSH & $0.01(p=0.670)$ & -0.05 & -0.01 & 0.641 \\
\hline eGFR & $-0.15(p<0.001)$ & -0.04 & -0.18 & $<0.001$ \\
\hline $\mathrm{HbA1c}$ & $0.01(p=0.804)$ & 0.16 & 0.03 & 0.250 \\
\hline \multicolumn{5}{|c|}{ Subclinical Hypothyroidism } \\
\hline No of participants & & 88 & & \\
\hline Sex (Men) & $0.06(p=0.580)$ & 0.55 & 0.08 & 0.472 \\
\hline Age & $0.15(p=0.163)$ & 0.07 & 0.19 & 0.095 \\
\hline free $\mathrm{T} 3$ & $0.03(p=0.809)$ & -0.53 & -0.05 & 0.674 \\
\hline TSH & $-0.10(p=0.360)$ & -0.10 & -0.05 & 0.625 \\
\hline eGFR & $0.09(p=0.429)$ & 0.04 & 0.16 & 0.166 \\
\hline $\mathrm{HbA} 1 \mathrm{c}$ & $-0.26(p=0.014)$ & -0.86 & -0.26 & 0.014 \\
\hline
\end{tabular}

$\triangle \mathrm{GFR}$, change in estimated glomerular filtration rate; eGFR, estimated glomerular filtration rate; T3, triiodothyronine; TSH, thyroid-stimulating hormone; HebA1, hemoglobin A1c; r $(p)$, simple correlation coefficient ( $p$ value); , parameter estimate; $\beta$, standardized parameter estimate. 
3.5. Correlations between Annual $\triangle e G F R$ and HbA1c among Non-SCH Status by Using Age-Matched Model

Table 5 shows the correlations between annual $\triangle \mathrm{eGFR}$ and HbA1c among non-SCH by using an age-matched model. In the simple correlation analysis, there was no significant correlation between $\mathrm{HbA} 1 \mathrm{c}$ and annual $\triangle \mathrm{eGFR}$. This association was unchanged even when further adjusted for known confounding factors.

Table 5. Simple correlation analysis and multiple linear regression analysis of annual $\Delta \mathrm{eGFR}$ and relevant factors among non-subclinical hypothyroidism by using age-matched sample.

\begin{tabular}{ccccc}
\hline & $\begin{array}{c}\text { Simple Correlation } \\
\text { Analysis }\end{array}$ & \multicolumn{2}{c}{ Multiple Linear Regression Analysis } \\
\cline { 2 - 5 } & $\mathbf{r}(\boldsymbol{p})$ & $\mathbf{B}$ & $\boldsymbol{\beta}$ & $\boldsymbol{p}$ \\
\hline \multicolumn{5}{c}{ Non-Subclinical Hypothyroidism } \\
\hline No of participants & 176 & -0.14 & 0.107 \\
Sex (Men) & $-0.11(p=0.138)$ & -0.83 & 0.01 \\
Age & $0.03(p=0.690)$ & 0.002 & -0.03 & 0.745 \\
free T3 & $-0.09(p=0.239)$ & -0.26 & -0.02 & 0.774 \\
TSH & $0.004(p=0.959)$ & -0.09 & -0.13 & 0.112 \\
eGFR & $-0.14(p=0.080)$ & -0.03 & 0.13 & 0.105 \\
HbA1c & $0.11(p=0.173)$ & 0.55 & \\
\hline
\end{tabular}

T3, triiodothyronine; TSH, thyroid-stimulating hormone; eGFR, glomerular filtration rate; HebA1, hemoglobin A1c; $r(p)$, simple correlation coefficient ( $p$ value); B, parameter estimate; $\beta$, standardized parameter estimate.

3.6. Correlations between $\triangle e G F R$ and HbA1c by SCH Status among Participants Who Were Not Taking Glucose-Lowerung Medication

Since glucose-lowering medication use could influence $\mathrm{HbA1c}$ values, it might act as a strong confounding factor in the present analysis. Thus, we performed an additional analysis of participants who were not taking glucose-lowering medication. The associations were essentially the same (Table 6).

Table 6. Simple correlation analysis and multivariable linear regression analysis of annual $\triangle \mathrm{eGFR}$ and relevant factors by subclinical hypothyroidism status among participants who were not taking glucose-lowering medication.

\begin{tabular}{|c|c|c|c|c|}
\hline & \multirow{2}{*}{$\begin{array}{c}\text { Simple Correlation } \\
\text { Analysis }\end{array}$} & \multicolumn{3}{|c|}{ Multiple Linear Regression Analysis } \\
\hline & & B & $\beta$ & $p$ \\
\hline \multicolumn{5}{|c|}{ Non-Subclinical Hypothyroidism } \\
\hline No of participants & & 141 & & \\
\hline Sex (Men) & $-0.08(p=0.002)$ & -0.54 & -0.09 & 0.002 \\
\hline Age & $-0.04(p=0.115)$ & -0.03 & -0.08 & 0.003 \\
\hline free T3 & $-0.02(p=0.566)$ & 0.30 & 0.03 & 0.267 \\
\hline TSH & $0.01(p=0.746)$ & -0.04 & -0.11 & 0.690 \\
\hline eGFR & $-0.13(p<0.001)$ & -0.04 & -0.16 & $<0.001$ \\
\hline $\mathrm{HbA1c}$ & $0.02(p=0.424)$ & 0.19 & 0.03 & 0.266 \\
\hline \multicolumn{5}{|c|}{ Subclinical Hypothyroidism } \\
\hline No of participants & & 77 & & \\
\hline Sex (Men) & $0.17(p=0.139)$ & 1.63 & 0.24 & 0.049 \\
\hline Age & $0.19(p=0.101)$ & 0.09 & 0.24 & 0.050 \\
\hline free $\mathrm{T} 3$ & $0.04(p=0.760)$ & -1.52 & -0.14 & 0.261 \\
\hline TSH & $-0.07(p=0.550)$ & -0.33 & -0.16 & 0.172 \\
\hline
\end{tabular}


Table 6. Cont.

\begin{tabular}{ccccc}
\hline & $\begin{array}{c}\text { Simple Correlation } \\
\text { Analysis }\end{array}$ & \multicolumn{2}{c}{ Multiple Linear Regression Analysis } \\
\cline { 2 - 5 } & $\mathbf{r}(p)$ & $\mathbf{B}$ & $\boldsymbol{\beta}$ & $\boldsymbol{p}$ \\
\hline eGFR & $-0.001(p=0.993)$ & 0.03 & 0.12 & 0.331 \\
HbA1c & $-0.28(p=0.015)$ & -1.14 & -0.32 & 0.006 \\
\hline
\end{tabular}

$\triangle \mathrm{GFR}$, change in estimated glomerular filtration rate; eGFR, estimated glomerular filtration rate; T3, triiodothyronine; TSH, thyroid-stimulating hormone; HbA1c, hemoglobin A1c; r $(p)$, simple correlation coefficient ( $p$ value); , parameter estimate; $\beta$, standardized parameter estimate.

\section{Discussion}

The main finding of the present longitudinal study is that higher $\mathrm{HbA1c}$ is significantly associated with reduced eGFR in participants with SCH but not in those without $\mathrm{SCH}$. Even when limited to participants who were not taking glucose-lowering medication, the associations were essentially the same. However, the mechanisms underlying the present results have not yet been clarified. We performed a multi-faceted analysis to clarify the mechanisms that could potentially explain the present results. A summary of the potential mechanism is shown in Figure 3. Associations shown in red (Figure 3a-f) were observed in the present study. Endothelial repair activated by endothelial injury, which is associated with hyperglycemia, might play an important role.

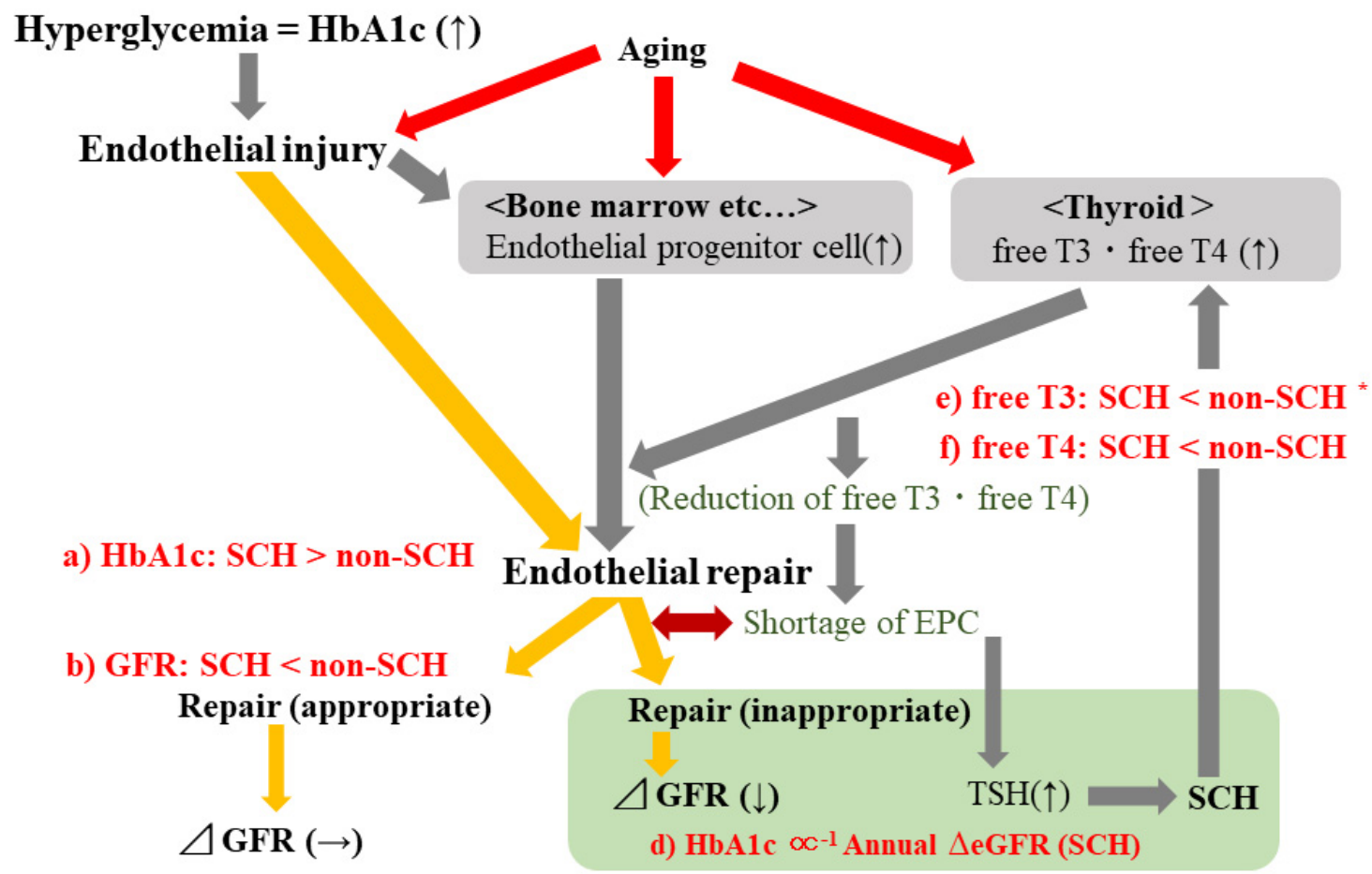

c) HbA1c $\chi^{-1}$ Annual $\triangle$ eGFR (non-SCH)

Figure 3. Potential mechanisms underlying the present results. Associations shown in red (a-f) were observed in the present study. TSH, thyroid-stimulating hormone; T3, triiodothyronine; T4, thyroxine; eGFR, estimated glomerular filtration rate; $\mathrm{SCH}$, subclinical hypothyroidism; Annual $\triangle$ eGFR: annual change in estimated glomerular filtration rate $\left(\left[\mathrm{mL} / \mathrm{min} / 1.73 \mathrm{~m}^{2}\right] /\right.$ year $) .{ }^{*}$ Nonstatistically significant association.

Previous case-control studies that involved patients with $\mathrm{SCH}$ (diagnosed as mild elevation in TSH levels with normal free T3 and free T4 levels) and age- and gendermatched normal controls (defined as TSH, free T3, and free T4 levels being in the normal range) showed a significant positive correlation between insulin resistance as evaluated 
by homeostasis model assessment-insulin resistance (HOMA-IR) and TSH [15]. Increased insulin resistance is a well-known cause of type 2 diabetes. In the present study, participants with SCH had significantly higher baseline values of $\mathrm{HbA1c}$ than participants without SCH (Table 1). Furthermore, the analysis that was limited to participants who were not taking glucose-lowering medication showed essentially the same association; the corresponding $\mathrm{HbA} 1 \mathrm{c}$ values were $5.8 \pm 0.9 \%$ for participants with $\mathrm{SCH}$ and $5.5 \pm 0.5 \%$ for participants without SCH $(p<0.001)$. Therefore, SCH could be associated with higher baseline HbA1c (Table 1, Figure 3a).

A previous meta-analysis reported a positive association between SCH and a higher risk of chronic kidney disease (CKD) [16]. Furthermore, a previous hospital-based casecontrol study with 3270 euthyroid patients with type 2 diabetes and 545 patients with type 2 diabetes and SCH reported that SCH could be a significant risk factor for CKD in patients with diabetes [17]. The findings of these studies are compatible with our present results that showed baseline renal function as evaluated by baseline eGFR in participants with $\mathrm{SCH}$ was significantly lower than that of participants without $\mathrm{SCH}$ (Table 1, Figure 3b). Our longitudinal analysis revealed a significant correlation between baseline $\mathrm{HbA} 1 \mathrm{c}$ and renal function as evaluated by annual $\triangle \mathrm{eGFR}$ only among participants with SCH (Tables 3, 4 and 6, Figure 3c,d). However, a high prevalence of diabetes among $\mathrm{SCH}[18]$ could not explain the significant association between $\mathrm{HbA} 1 \mathrm{c}$ and annual $\triangle \mathrm{eGFR}$ in participants with SCH. By using multivariable model, a significant association between $\mathrm{HbA} 1 \mathrm{c}$ and annual $\triangle \mathrm{eGFR}$ was observed even when the analysis was performed limited to SCH without diabetes (Table 3). Furthermore, the status of diabetes did not influence the association between $\mathrm{HbA} 1 \mathrm{c}$ and annual $\triangle \mathrm{eGFR}$ (Table 2). Therefore, the status of diabetes might not act as a determinant on the association between $\mathrm{HbA} 1 \mathrm{c}$ and annual $\triangle \mathrm{eGFR}$.

Hyperglycemia, which is associated with higher $\mathrm{HbA1c}$ levels, is known to induce endothelial dysfunction [8]. Endothelial dysfunction is recognized as one of the upstream mechanisms that leads to glomerular injury, which is associated with lower eGFR [9]. Since endothelial progenitor cells contribute to endothelial repair, the presence of endothelial injury stimulates the production of endothelial progenitor cells [7]. Our previous studies showed that higher levels of circulating endothelial progenitor cells (CD34-positive cells) are associated with higher HbA1c values [7,19,20]. However, the number of endothelial progenitor cells and their functions are reported to be decreased with advancing CKD [21]. Reduction in the number of endothelial cells due to consumption [22] might lead to an inverse relationship between endothelial progenitor cell count and CKD.

On the other hand, thyroid hormones directly stimulate hematopoietic stem cells, which differentiate into endothelial progenitor cells [2]. Therefore, a relative shortage of endothelial progenitor cells could be associated with increased TSH production, which results in SCH. In other words, participants with $\mathrm{SCH}$ might have a relative deficiency of endothelial progenitor cells that results in a lower ability to maintain renal function.

In addition, lower levels of thyroid hormones due to consumption could occur in participants with aggressive endothelial repair since thyroid hormones directly stimulate hematopoietic stem cells [2]. Thyroid hormone levels are lower in participants with SCH than in participants without SCH, as we showed in the present study (Table 1, Figure 3e,f). Hematopoietic activity in the bone marrow declines with age [23] and aging is also a well-known cause of endothelial injury [24,25]. However, decreased thyroid function, as well as TSH levels may contribute to the increased lifespan [26]. Demands for thyroid hormone might decrease with aging [27]. TSH levels could increase with the aging process, regardless of whether there is actual thyroid disease [28]. However, the influence of age on the present main associations should be limited. In the present study, participants with SCH were older than participants without SCH, even though the difference was not statistically significant (Table 1). Furthermore, in the main results, significant association between $\mathrm{HbA} 1 \mathrm{c}$ and annual $\triangle \mathrm{eGFR}$ were observed among participants with SCH even after adjusted for age (Tables 3,4 and 6). 
Therefore, inappropriate endothelial repair activity might lead to the development of $\mathrm{SCH}$. To clarify this mechanism, further investigation with information about endothelial progenitor cells is necessary.

From the clinical perspective, the present study demonstrated that SCH status could act as an effect modifier on the association between $\mathrm{HbA} 1 \mathrm{c}$ and renal function. Therefore, treatment of SCH could be an efficient strategy for preventing diabetic nephropathy. Furthermore, even though further investigation is necessary, this study also suggests that the presence of SCH could indicate the presence of inappropriate endothelial repair.

Potential limitations of this study warrant consideration. Excessive consumption of iodine and the presence of autoimmune antibodies or congenital factors are known to be associated with thyroid function. Those factors could act as confounders but we do not have any data on them. However, our present analysis was performed among participants without any history of thyroid disease. Even though endothelial progenitor cells might play an important role in the mechanisms underlying the present results, we have no data about endothelial progenitor cells because of the difficulty in measuring those cells in routine health examinations. Further studies with those data are necessary.

\section{Conclusions}

In conclusion, the disadvantage of elevated $\mathrm{HbA1c}$ on renal function is observed only among participants with SCH. SCH status could act as an effect modifier on the association between $\mathrm{HbA} 1 \mathrm{c}$ and renal function.

Author Contributions: Conceptualization, Y.S. and T.M.; methodology, Y.S., S.-Y.K., S.N., Y.N. (Yasuhiro Nagata), T.M. and N.H; software Y.S., Y.N. (Yuko Noguchi), and N.H.; validation Y.S., Y.N. (Yuko Noguchi), T.M. and N.H.; formal analysis, Y.S. and Y.N. (Yuko Noguchi); investigation, Y.S.; resources, all authors; data curation, all authors; writing original draft preparation, Y.S.; writingreview and editing, Y.S.; visualization, Y.S., Y.N. (Yuko Noguchi), T.M. and N.H.; supervision, T.M. and N.H.; project administration, Y.S.; funding acquisition, T.M. All authors have read and agreed to the published version of the manuscript.

Funding: This study was supported by the Japan Society for the Promotion of Science (No. 21H02575).

Institutional Review Board Statement: This study was approved by the Ethics Committee of Nagasaki University Graduate School of Biomedical Sciences (project registration number 14051404). This manuscript as written based on the STROBE statement to assess the reporting of cohort and cross-sectional studies. All procedures involving human participants in this study were performed in accordance with the ethical standards of the institution research committee and the 1964 Helsinki Declaration, and its later amendments for comparable ethical standards.

Informed Consent Statement: Written consent forms were used to ensure that participants understood the objectives of the study when obtaining informed consent.

Data Availability Statement: We cannot publicly provide individual data due to participant privacy, according to ethical guidelines in Japan. Additionally, the informed consent obtained does not include a provision for publicity-sharing data. Qualifying researchers may apply to access a minimal dataset by contacting Prof Naomi Hayashida, Principal Investigator, Division of Promotion of Collaborative Research on Radiation and Environment Health Effects, Atomic Bomb Disease Institute, Nagasaki University, Nagasaki, Japan at naomin@nagasaki-u.ac.jp. Or, please contact the office of data management at ritouken@vc.fctv-net.jp. Information for where data request is also available online: https:/ / www.genken.nagasaki-u.ac.jp/dscr/message/ and http://www.med.nagasaki-u.ac.jp/cm/ (accessed on 12 January 2022).

Acknowledgments: We are grateful to staff from Saza town office for their outstanding support.

Conflicts of Interest: The authors declare no conflict of interest. 


\section{References}

1. Lu, M.; Yang, C.-B.; Gao, L.; Zhao, J.-J. Mechanism of subclinical hypothyroidism accelerating endothelial dysfunction (Review). Exp. Ther. Med. 2015, 9, 3-10. [CrossRef] [PubMed]

2. Vacek, A.; Rotkovská, D.; BartoniČková, A.; Pospísiil, M. Effect of hyperthyroidism on haemopoietic stem cell kinetics in mice. Cell Prolif. 1978, 11, 487-496. [CrossRef]

3. Daub, K.; Langer, H.; Seizer, P.; Stellos, K.; May, A.E.; Goyal, P.; Bigalke, B.; Schönberger, T.; Geisler, T.; Siegel-Axel, D.; et al. Platelets induce differentiation of human CD34+ progenitor cells into foam cells and endothelial cells. FASEB J. 2006, 20, $2559-2561$. [CrossRef] [PubMed]

4. Stellos, K.; Langer, H.; Daub, K.; Schoenberger, T.; Gauss, A.; Geisler, T.; Bigalke, B.; Mueller, I.; Schumm, M.; Schaefer, I.; et al. Platelet-derived stromal cell-derived factor-1 regulates adhesion and promotes differentiation of human CD34+ cells to endothelial progenitor cells. Circulation 2008, 117, 206-215. [CrossRef]

5. Villacorte, M.; Delmarcelle, A.-S.; Lernoux, M.; Bouquet, M.; Lemoine, P.; Bolsée, J.; Umans, L.; Lopes, S.C.D.S.; van der Smissen, P.; Sasaki, T.; et al. Thyroid follicle development requires Smad1/5- and endothelial cell-dependent basement membrane assembly. Development 2016, 143, 1958-1970. [CrossRef] [PubMed]

6. Degosserie, J.; Heymans, C.; Spourquet, C.; Halbout, M.; D'Auria, L.; van der Smissen, P.; Vertommen, D.; Courtoy, P.J.; Tyteca, D.; Pierreux, C.E. Extracellular vesicles from endothelial progenitor cells promote thyroid follicle formation. J. Extracell. Vesicles 2018, 7, 1487250. [CrossRef]

7. Shimizu, Y.; Yamanashi, H.; Noguchi, Y.; Koyamatsu, J.; Nagayoshi, M.; Kiyoura, K.; Fukui, S.; Tamai, M.; Kawashiri, S.-Y.; Kondo, H.; et al. Association between chronic kidney disease and carotid intima-media thickness in relation to circulating CD34-positive cell count among community-dwelling elderly Japanese men. Atherosclerosis 2019, 283, 85-91. [CrossRef]

8. Meza, C.A.; La Favor, J.D.; Kim, D.-H.; Hickner, R.C. Endothelial dysfunction: Is there a hyperglycemia-induced imbalance of NOX and NOS? Int. J. Mol. Sci. 2019, 20, 3775. [CrossRef]

9. Endemann, D.H.; Schiffrin, E.L. Endothelial dysfunction. J. Am. Soc. Nephrol. 2004, 15, 1983-1992. [CrossRef]

10. Kang, S.H.; Jung, D.J.; Choi, E.W.; Cho, K.H.; Park, J.W.; Do, J.Y. HbA1c levels are associated with chronic kidney disease in a non-diabetic adult population: A nationwide survey (KNHANES 2011-2013). PLoS ONE 2015, 10, e0145827. [CrossRef]

11. Shimizu, Y.; Nabeshima-Kimura, Y.; Kawashiri, S.-Y.; Noguchi, Y.; Nagata, Y.; Maeda, T.; Hayashida, N. Anti-thyroid peroxidase antibody and thyroid cysts among the general Japanese population: A cross-sectional study. Environ. Health Prev. Med. 2020, $25,7$. [CrossRef]

12. LSI Medience Corporation Information. Rinsyokensa Jugyo. 2017. 17-04 C-01. Available online: http:/ / www.medience.co.jp/ information/02.html (accessed on 12 January 2022).

13. Seino, Y.; Nanjo, K.; Tajima, N.; Kadowaki, T.; Kashiwagi, A.; Araki, E.; Ito, C.; Inagaki, N.; Iwamoto, Y.; Kasuga, M.; et al. Report of the committee on the classification and diagnostic criteria of diabetes mellitus. Diabetol. Int. 2010, 1, 2-20. [CrossRef]

14. Imai, E.; Horio, M.; Watanabe, T.; Iseki, K.; Yamagata, K.; Hara, S.; Ura, N.; Kiyohara, Y.; Moriyama, T.; Ando, Y.; et al. Prevalence of chronic kidney disease in the Japanese general population. Clin. Exp. Nephrol. 2009, 13, 621-630. [CrossRef] [PubMed]

15. Sengupta, S.; Jaseem, T.; Ambalavanan, J.; Hegde, A. Homeostatic model assessment-insulin resistance (HOMA-IR 2) in mild subclinical hypothyroid subjects. Indian J. Clin. Biochem. 2018, 33, 214-217. [CrossRef] [PubMed]

16. Wang, X.; Zhao, X.; Huang, X. Association of subclinical thyroid dysfunction with chronic kidney disease: A systematic review and meta-analysis. Endocr. Res. 2019, 45, 41-49. [CrossRef] [PubMed]

17. Zhou, J.-B.; Li, H.-B.; Zhu, X.-R.; Song, H.-L.; Zhao, Y.-Y.; Yang, J.-K. Subclinical hypothyroidism and the risk of chronic kidney disease in T2D subjects: A case control and dose-response analysis. Medicine 2017, 96, e6519. [CrossRef] [PubMed]

18. Han, C.; He, X.; Xia, X.; Li, Y.; Shi, X.; Shan, Z.; Teng, W. Subclinical hypothyroidism and type 2 diabetes: A systematic review and meta-analysis. PLoS ONE 2015, 10, e0135233. [CrossRef]

19. Shimizu, Y.; Kawashiri, S.-Y.; Kiyoura, K.; Nobusue, K.; Yamanashi, H.; Nagata, Y.; Maeda, T. Gamma-glutamyl transpeptidase $(\gamma-\mathrm{GTP})$ has an ambivalent association with hypertension and atherosclerosis among elderly Japanese men: A cross-sectional study. Environ. Health. Prev. Med. 2019, 24, 69. [CrossRef]

20. Shimizu, Y.; Sato, S.; Koyamatsu, J.; Yamanashi, H.; Nagayoshi, M.; Kadota, K.; Kawashiri, S.-Y.; Inoue, K.; Nagata, Y.; Maeda, T. Platelets and circulating CD34-positive cells as an indicator of the activity of the vicious cycle between hypertension and endothelial dysfunction in elderly Japanese men. Atherosclerosis 2017, 259, 26-31. [CrossRef]

21. Krenning, G.; Dankers, P.Y.; Drouven, J.W.; Waanders, F.; Franssen, C.F.; van Luyn, M.J.; Harmsen, M.C.; Popa, E.R. Endothelial progenitor cell dysfunction in patients with progressive chronic kidney disease. Am. J. Physiol. Renal. Physiol. 2009, 296, F1314-F1322. [CrossRef]

22. Shimizu, Y.; Kawashiri, S.-Y.; Kiyoura, K.; Koyamatsu, J.; Fukui, S.; Tamai, M.; Nobusue, K.; Yamanashi, H.; Nagata, Y.; Maeda, T. Circulating CD34+ cells and active arterial wall thickening among elderly men: A prospective study. Sci. Rep. 2020, 10, 4656. [CrossRef] [PubMed]

23. Garvin, K.; Feschuk, C.; Sharp, J.G.; Berger, A. Does the number or quality of pluripotent bone marrow stem cells decrease with age? Clin. Orthop. Relat. Res. 2007, 465, 202-207. [CrossRef]

24. Ungvari, Z.; Tarantini, S.; Donato, A.J.; Galvan, V.; Csiszar, A. Mechanisms of vascular aging. Circ. Res. 2018, 123, 849-867. [CrossRef] 
25. Rea, I.M.; Gibson, D.S.; McGilligan, V.; McNerlan, S.E.; Alexander, H.D.; Ross, O.A. Age and age-related diseases: Role of inflammation triggers and cytokines. Front. Immunol. 2018, 9, 586. [CrossRef]

26. Gesing, A.; Lewiński, A.; Karbownik-Lewińska, M. The thyroid gland and the process of aging; what is new? Thyroid Res. 2012, 5, 16. [CrossRef]

27. Shimizu, Y.; Kawashiri, S.-Y.; Noguchi, Y.; Nagata, Y.; Maeda, T.; Hayashida, N. Association between thyroid cysts and hypertension by atherosclerosis status: A cross-sectional study. Sci. Rep. 2021, 11, 13922. [CrossRef]

28. Calsolaro, V.; Niccolai, F.; Pasqualetti, G.; Calabrese, A.M.; Polini, A.; Okoye, C.; Magno, S.; Caraccio, N.; Monzani, F. Overt and subclinical hypothyroidism in the elderly: When to treat? Front. Endocrinol. 2019, 10, 177. [CrossRef] [PubMed] 